\title{
Innovation and Practice to Improve Mechanical Manufacturing Students' Cognition Practice Diversity
}

\author{
Yanying Wang* \\ Dalian University \\ The Academic of Produce Engineering \\ Dalian city, Liaoning, China \\ 565283290@qq.com
}

\begin{abstract}
Cognition practice is the first professional practice course for mechanical students. The mechanical manufacturing major of Dalian university has developed a new mode of diversified cognition practice based on years of research experience: to unite the content of practice with ideas of innovation and starting business while keeping the original practice links. To improving practice quality by implementing better practice preparation, practice contents, practice method, rating method and time management. By means of this round of educational reform, the target of establishing a correct professional concept and motivating the enthusiasm of learning the profession was reached, and the cognition practice has also become popular with students, whose practicing ability and innovation capacity are also greatly improved.
\end{abstract}

Keywords-Mechanical Major, Cognition Practice, Innovation and Practice, Diversity

\section{INTRODUCTION}

Cognition practice is the first practical course of mechanical student after entering the school, which has professional attributes. It is arranged at the end of the second semester of sophomore year, and the time is one week. In order to ensure the quality of cognition practice, since 2016, the mechanical manufacturing institute of Dalian university has constructed a kind of diversity cognition practice mode based on practice and exploration for many years. This mode remains the original internship, but combines innovation and entrepreneurship. And then, to set about from practice preparation, practice content, practice methods, evaluation methods and practice time management and so on, to improve the quality of internship, to form solid professional thought. Finally, reach the target of establishing a correct professional concept and motivating the enthusiasm of the profession learning. According to the feedback from students in recent two years, the results are quite remarkable.

\section{TRAditional PRACTICE MODE ANALYSIS[1-5]}

\section{A. Based construction for practice is insufficient}

Firstly, in terms of safe production and economic benefits, the enterprises are not willing to accept short-term internship because these tasks belong to the extra work for the enterprises and will increase the potential safety hazard; Secondly, all internship works have to avoid the important production within enterprises plan. So, the internship plan must be revised over and over again before getting the final one.

\section{B. Lack of standardized practice guidance}

It is an important link to visit the workshop of the enterprise in the cognition practice of machinery. The faculty advisor and students are usually guided by the enterprise personnel how to visit the factory. The professional knowledge level of enterprise personnel and faculty advisor and the on-site control have great influence on the effect of the internship. Currently, there is still short of assessment mechanism for guiding personnel and faculty advisor in the internship. The phenomenon of "herding sheep" has occurred frequently, which greatly reduces the positivity of internship.

\section{The function of faculty advisor is inadequate}

The cognition practice is usually one week in china. In most cases, there are two faculty advisors to take lead a class student to practice in several manufactories. The most of mechanical practice will select mechanical entrepreneurship, such as machine tools, mold design, machinery and equipment manufacturing, which relate to a lot of products, technical requirement, process, equipment and fixtures. It means the whole information quantities are very large. Sometimes, the visiting route still must be adjusted in time according to entrepreneurship produce plan. At the same time, the faculty advisor must ensure all students safe. So, it is the faculty advisor with many years guidance experience to feel the ability not equal to his ambitions when facing so many complex conditions. Thus, the cognition practice can't reach original target and will become a kind of form.

\section{Students are lack of positivity of practice}

For the traditional practice, the practice mobilization meeting focuses on safety education. There is not any professional explanation on visiting enterprises and professional lectures on subjects. Thus, the internship can't master the practice contents and practice aim. So, the practice preparation and the degree of recognition can't be expected to be higher. You can imagine that thus practice will be lost.

Dalian University Teaching Reform Project 
Some enterprises make visiting finish quickly for enterprises safety and productivity efficiency. All of them will influence on students' positivity of the cognition practice.

\section{E. The performance evaluation is not perfect.}

The students' performance of cognition practice is generally made up of the personal performance, the internship report and internship summary. Currently, Internship performance evaluations are still short of evaluation basis and evaluation standard is not clear. The quantitative indicators for cognition practice are very little and the degree of differentiation is not obvious. Thus, it made the internship report become day-to-day journal account and the internship summary was written as sentiment. In a word, the whole cognition practice can't reflect the professional features.

\section{F. No way to demonstrate the innovation ability sufficiently}

The most cognition practice is under lead of faculty advisor. Usually, the visiting students walk past factory and get nothing. In addition, there are no incentive measurements for cognition practice performance. In most cases, the students can get good performance if they do the internship report well. But, the on- site visiting as the most important link is often neglected. Thus, the enthusiasm of cognition practice will be killed and the function of training innovation ability can't be implemented in cognition practice.

\section{The New Cognitive Mode AND Implementation Plan}

\section{A. Internship management and its system}

Under the university and academic management system, to make reform ideas and construction content much clearer and to make new cognition mode propels and implement actively. To represent major knowledge to students by seminar and video according to discipline before kicking off cognition practice. And then, to take lead students to visit the training center, professional exhibition and practice site under the guidance of faculty advisor following the action plan. Thus, the capability of cognition, practice and innovation can be established for students. This solution involves the guidance of faculty advisor and individual communication, which make the whole cognition run progressively. Thus, a cognition practice system with combining engineering thought and practice is built. Please see Fig. 1.

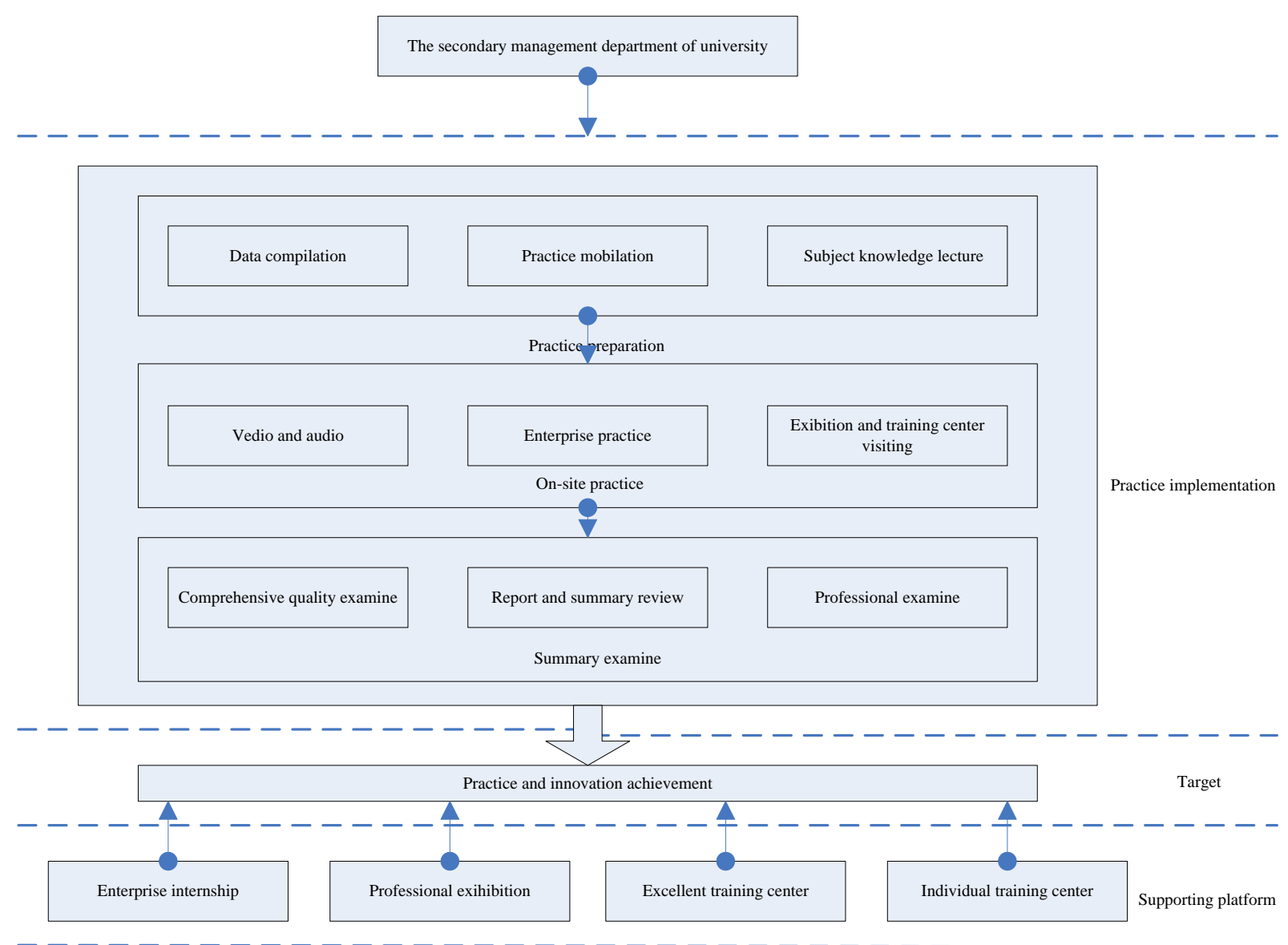

Fig. 1. Implementing flow chart for practice reform 


\section{B. Innovative cognition practice}

The Innovative cognition mainly involves two parts: preparation and field visit:

\section{1) Preparation in advance}

(1) To choose the well-made documentary in advance. By playing them at the right time, to make the students understood the importance and significance of mechanical industry in the national economic construction. At the same time, let the students know about the technical level and developing trend of machinery industry, let the students to have professional literacy and have the sense of mission to become a mechanical specialist in future.

(2) To carry out specialized knowledge lecture based on the professional curriculum setting and the innovation idea of the science and technology. And then, to make the overall the subject knowledge optimized. To play the professional video of the internship enterprise which is recorded elaborately before and make the students know about the relevant contents of the equipment and processing technology related to this major in the preparation stage.

(3) Before entering the factory, do the internship mobilization well, mainly including the safety education and the safety agreement with the students so that ensure the internship safe and orderly.

\section{2) Field visit}

(1) By visiting the mechanical exhibition, let the students learn about the latest mechanical products and equipment, and touch the brands and products of famous machinery manufacturers at home and abroad. Understand and find the enterprises and products that meet their own professional and interests, and cultivate mechanical quality.

(2) through a tour of the engineering training center, to deepen the cognition and understanding of the students to processing equipment (conventional machining, CNC processing, special processing, rapid prototyping, etc.) and the related processing mode, thereby, to establish the basic impression for the relevant mechanical processing manufacturing.

(3) Through a tour of the outstanding enterprises related to mechanical factory, make the students understand the composition and the organization, operation for the manufacturing enterprise, so as to get perceptual knowledge for the factory.

(4) Through the communication with factory technical and management, to make the students have a preliminary understanding for work environment, job responsibilities and professional knowledge level for the mechanical professional and technical personnel, which benefit to help the students to think about their own professional development goals.

\section{The comparison between existing status and after innovation}

TABLE I is the comparison between existing status and after innovation reform, including the preparation, content, process and KPI.

TABLE I. THE COMPARISON BETWEEN BEFORE AND AFTER INNOVATIVE COGNITION PRACTICE

\begin{tabular}{|c|c|c|}
\hline content & Existing status & The new adding after innovation \\
\hline Preparation & $\begin{array}{l}\text { Contact enterprise (2) Safety } \\
\text { education and discipline demand }\end{array}$ & $\begin{array}{l}\text { (3) Select appropriate professional audio and video materials; (4) Choose } \\
\text { the appropriate professional exh ibition; (5) Pro fessional subject lectures } \\
\text { (6) Prepare discussion topics; (7) Play the professional video recorded by } \\
\text { the internship enterprise }\end{array}$ \\
\hline Content & $\begin{array}{l}\text { (1) Understand the enterprise and its } \\
\text { main products (2) Know about the } \\
\text { machining and manufacturing roughly }\end{array}$ & $\begin{array}{l}\text { (3) To understand the design, manufacture, debugging, testing and sales } \\
\text { of regional characteristic mechanical products; (4) Know about typical } \\
\text { products and equipment of the famous enterprise and their status, level } \\
\text { and trend in the world (5) To understand the working environment, } \\
\text { responsibilities and professional knowledge, to think actively and plan } \\
\text { professionaldevelopment goals. }\end{array}$ \\
\hline process & (1) Visit the factory. & $\begin{array}{l}\text { (2) To see the audio and video (3) visit the training center (4) visit the } \\
\text { professionalexhibition (5) professionalseminar }\end{array}$ \\
\hline KPI & $\begin{array}{l}\text { (1) The attitude and the comprehensive } \\
\text { quality (2) the quality of internship } \\
\text { report and internship summary }\end{array}$ & $\begin{array}{l}\text { (3) Team spirit and positivity (4) professional presentation (5) questions } \\
\text { quantity on site. }\end{array}$ \\
\hline
\end{tabular}

\section{The EfFect of Diversified Cognition Practice REFORM}

For making the cognition practice within a week achieve the better effect, there are many actions have to be implemented well, involving internship survey, preparation, contact, the professional knowledge ignition and so on.

Through more than two years of reform, the way for students to acquire practical knowledge on site was expanded greatly.
A. It cultivates the professional quality of mechanical students and enhances their ability to participate in practice.

Through mechanical pluralistic cognition practice reform, the students learnt how to think and validate the professional theoretical knowledge in practice. The most of students like to visit the field with the questions. Comparing to before, the mechanical quality and practice ability were improved so much. 


\section{B. The students' sense of mission was motivated and the initiative of learning was improved}

Through a tour of the international machinery exhibition, to make the students understand the Chinese machinery industry development and to motivate the students the sense of responsibility and mission to learn the major. The practice base is selected according to the future career prospect and major course.

\section{Mining and cultivate the students' innovation consciousness and innovation ability.}

Because of practicing on-site, watching a well-made audio data, visiting the advanced training center and professional exhibition, the understanding competence of the students for subject study were improved greatly. At the same time, the engineering thinking and innovative ability were also being increased greatly.

\section{Summary}

Through more than 2 years reform and practice exploration, this new cognition practice has obtained the good effect. It not only increases the effect of cognition practice but also deepen the awareness of mechanical professional knowledge. Thus, it makes more and more students start to like and love mechanical major. Now, the mechanical cognition practice has become the favorite course in Dalian university.

\section{REFERENCES}

[1] Yang Yuanmo, WangXiaojun, Peng Shu. The construction and practice of mechanical major teaching system Based on the "outstanding engineers training plan". Journal of Guangdong technical teacher college, 2017 (6): 51-56. (In Chinese)

[2] Li Xinmo, Geng Ainong. The reform and exploration of multidimensional model of cognition practice for mechanical or electrical major, the new curriculum research, 2016 (05): 22-24. (In Chinese)

[3] Wei Xiaoling, Fan Zhihong, Wang Jianing. The study on mechanical practical teaching system based on cultivating the ability of innovation research. Journal of Hebei engineering university (social science edition), 2016 (03): 103-106. (In Chinese)

[4] Li Xiaojun. The construction and exploration of practical teaching system for mechanical engineering. Hunan agricultural machinery 2012 33 (1): 6 163165. (In Chinese)

[5] Guo Zhongning, Luo Shaoming, Zhang Xiangwei. Practical teaching system construction and implementation of mechanical engineering. The experimental technology and management, 2009 (6): 15 to 17, 22. (In Chinese) 